Full Length Article

\title{
Adherence challenges encountered in an intervention programme to combat chronic non-communicable diseases in an urban black community, Cape Town
}

\author{
Nasheetah Solomons ${ }^{a,{ }^{*}}$, Herculina Salomé Kruger ${ }^{b}$, Thandi Rose Puoane ${ }^{c}$ \\ ${ }^{a}$ Department of Dietetics and Nutrition, University of the Western Cape, South Africa \\ ${ }^{\mathrm{b}}$ Centre of Excellence for Nutrition, North-West University, Potchefstroom, South Africa \\ c School of Public Health, University of the Western Cape, South Africa
}

\section{A R T I C L E I N F O}

Article history:

Received 14 April 2016

Accepted 14 November 2016

Keywords:

Adherence

Chronic non-communicable

diseases

Focus group discussion Intervention programme Non-adherence

\begin{abstract}
A B S T R A C T
Background: Chronic non-communicable diseases (CNCD) have become the greatest contributor to the mortality rate worldwide. Despite attempts by Governments and various non-governmental organisations to prevent and control the epidemic with various intervention strategies, the number of people suffering from CNCD is increasing at an alarming rate in South Africa and worldwide.

Objectives: Study's objectives were to explore perceived challenges with implementation of, and adherence to health messages disseminated as part of a CNCD intervention programme; to gain an understanding of participants' expectations of CNCD intervention programmes; , and to explore the acceptability and preference of health message dissemination methods. In addition, participants' awareness of, and willingness to participate in CNCDs intervention programmes in their community was explored.

Methods: Participants were recruited from the existing urban Prospective Urban Rural Epidemiology study site in Langa, Cape Town. Focus group discussions were conducted with 47 participants using a question guide. Summative content analysis was used to analyse the data. Results: Four themes emerged from the data analysis: practical aspects of implementation and adherence to intervention programmes; participants' expectations of intervention programmes; aspects influencing participants' acceptance of interventions; and their preferences for health message dissemination. The results of this study will be used to inform CNCDs intervention programmes.

Conclusions: Our findings revealed that although participants found current methods of health message dissemination in CNCDs intervention acceptable, they faced real challenges with implementing and adhering to CNCDs to these messages.

Copyright () 2016, The Authors. Publishing services by Elsevier B.V. on behalf of Johannesburg University. This is an open access article under the CC BY-NC-ND license

(http://creativecommons.org/licenses/by-nc-nd/4.0/).
\end{abstract}

\footnotetext{
* Corresponding author. Private Bag X17, Bellville, 7535, South Africa.

E-mail address: nsolomons@uwc.ac.za (N. Solomons).

Peer review under responsibility of Johannesburg University.

http://dx.doi.org/10.1016/j.hsag.2016.11.006

1025-9848/Copyright @ 2016, The Authors. Publishing services by Elsevier B.V. on behalf of Johannesburg University. This is an open access article under the CC BY-NC-ND license (http://creativecommons.org/licenses/by-nc-nd/4.0/).
} 


\section{Introduction}

Chronic non-communicable diseases (CNCD) - diseases that are non-transmissible and non-infectious - have been proven conclusively to be the main causes of adult morbidity and mortality, worldwide (Oli, Vaidya, \& Thapa, 2013; Whiteside, 2014). These diseases include diabetes, cardiovascular diseases, certain cancers and chronic respiratory diseases (Ezzati \& Riboli, 2012; Herrera-Cuenca, Castro, Mangia, \& Correa, 2014; Li, 2013). Currently, CNCD are responsible for more than $50 \%$ of the global disease burden, with an estimated $80 \%$ of associated deaths (Hunter \& Reddy, 2013; Isaacs et al., 2014; Levitt, Steyn, Dave, \& Bradshaw, 2011; Rossier, Souri, Duthe, \& Findley, 2014).

The rapid increase of CNCD in low- and middle-income countries is well documented. South Africa, however, is also experiencing this trend yet it is classified as an upper-middleincome country by the World Bank (2015) income classification (Alwan \& MacLean, 2009; Teo, Chow, Vaz, Rangarajan, \& Yusuf, 2009). According to Dalal et al. (2011), CNCD will be responsible for $46 \%$ of deaths in sub-Saharan Africa, with higher age-standardised death rates in four of these countries (DRC, Ethiopia, Nigeria and South Africa) compared to those in high-income countries.

Chronic non-communicable diseases which are attributable to modifiable risk factors including overweight, smoking, physical inactivity, high-fat energy-dense diets and alcohol use, hold serious consequences for national economic, socioeconomic and developmental growth. Because of their chronicity, these diseases place an increased demand on the healthcare sector, with an increasing number of persons requiring specialised care. In addition, the fact that many of those affected by CNCD are of working-age, affects the country's economic growth through productivity losses and prolonged disability (Ezzati \& Riboli, 2012; Muka et al., 2015).

The findings of the recent South African National Health and Nutrition Examination Survey (SANHANES-1) indicates that the South Africans surveyed, who had self-reported histories of CNCD, matched the CNCD profile - they were overweight or obese, consumed a high fat and refined carbohydrate diet, consumed excessive amounts of alcohol, smoked tobacco and were physically less active. The rates of self-reported history of CNCD were also the highest in formal urban areas (Shisana et al., 2013).

In 2006, the National Department of Health in South Africa developed national guidelines for the management and control of non-communicable diseases, comparable to international standards (Department of Health, 2006; Mayosi et al., 2009). However, these guidelines were not effectively implemented - they were not circulated widely enough, while the management of chronic diseases was not monitored, or reviewed (Mayosi et al., 2009). In addition, the efficacy of a number of community-based CNCD interventions that exist in South Africa is also unknown.

At a national Summit on Non-Communicable Diseases, organised by the South African Ministry of Health in September 2011, targets aimed at reducing CNCD in South Africa by the year 2020 were set (Mayosi et al., 2012). Despite the existence of various CNCD intervention strategies, implemented by government, or non-governmental organisations, to address the CNCD epidemic, the number of people becoming afflicted by CNCD is increasing (Mayosi et al., 2012).

Evidence in the literature reveals the success of interventions, such as weight control, dietary intake modification, increased physical activity and decreased use of, or cessation of the use of, alcohol and tobacco products, in combatting the development and management of CNCD (Drozek et al., 2014; Gortmaker et al., 2011; Merrill, Aldana, Greenlaw, Salberg, \& Englert, 2008). However, many adults still struggle to implement and adhere to healthy lifestyle behaviours (Murray et al., 2013).

The present study is embedded in the ongoing Prospective Urban Rural Epidemiological (PURE) study of the Western Cape cohort. The PURE study is a global longitudinal study involving 25 high-, low-, and middle-income countries seeking to identify the population level factors that drive the development of known risk factors for CNCD in adults (Teo et al., 2009). Langa, the site of the Western Cape urban cohort is a suburb near the city of Cape Town, with an estimated population of 25,987 of which $99 \%$ is black African. This community has an unemployment rate of $40 \%$ while $72 \%$ of the household has an average monthly income of R3 200 (Census, 2011).

\subsection{Research problem statement and objectives}

The increase in CNCD in South Africa has been attributed to the country being in a "nutrition transition" which is characterised by a diet high in saturated fat, sugar and refined foods, together with decreased levels of physical activity (Lategan, van den Berg, \& Walsh, 2014). The South African Government and non-governmental organisations are all striving to curb the spread of the CNCD epidemic by developing intervention programmes and creating awareness of these conditions. Information on how to prevent the development of CNCD is being disseminated by means of posters, pamphlets and various media [radio, television] (Puoane, Tsolekile, Sanders, \& Parker, 2008).

Despite these various attempts, statistics indicate that the prevalence of CNCD is continuing to increase (Statistics South Africa, 2014). Possible reasons for this may be socio-cultural, environmental (space), language barriers, modes of health message dissemination or lack of knowledge (Ebrahim, de Villiers, \& Ahmed, 2014; Ganiyu, Mabuza, Malete, Govender, \& Ogunbanjo, 2013). Context-based challenges to the implementation of and adherence to CNCD intervention programmes' health messages, awareness of community-based CNCD intervention programmes and the acceptability of these health messages have not been explored in South African black populations.

The objectives of this study, therefore, were to explore perceived challenges with implementation of and adherence to health messages disseminated as part of a CNCD intervention programme; to gain an understanding of participants' expectations of CNCD intervention programmes, and explore the acceptability and preference of health message dissemination methods in CNCD intervention programmes. Additionally, participants' awareness of existing CNCD intervention programmes in their community and their 
willingness to participate in these intervention programmes were also investigated. Results from this study will be presented at conferences and will serve to raise awareness for the need of health messages which are tailored to meet communities' context-based challenges.

\section{Method and materials}

\subsection{Study design and context}

This was a cross-sectional study which made use qualitative data collection methods. The focus group discussion (FGD) method was chosen for data collection, since this method encourages participants to express their personal views freely when conducted by a trained facilitator. In addition, a FGD is an efficient technique used for gaining a large amount of data regarding opinions and attitudes in the shortest amount of time (Masadeh, 2012).

This study was conducted in Langa. In the post-apartheid years Langa experienced a rapid population growth as a result of migration of people chiefly from the rural Eastern Cape (Census, 2011). The role of urbanisation and its consequent nutrition transition in the CNCD epidemic is welldocumented and since Langa is considered to be a community in transition it was considered an ideal site for the study (Lategan et al., 2014).

\subsection{Recruitment of study population}

Participants were purposively sampled from the ongoing PURE study. Inclusion criteria were being a male or female Langa resident, aged 35-70 years. A research assistant (RA) approached potential participants during the PURE study follow-up interviews that were conducted in 2015 for possible participation in the study. During the recruitment phase (1-30 April 2015) the RA explained the purpose of the study as well as what would be expected from them during the FGDs. At this stage confidentiality was explained and the potential participants were also made aware of their right to decline to participate in the study at any time.

\subsection{Data collection}

Discussions were conducted over a period of three months (May-July 2015) at the community hall in Langa. This location was chosen, first, because it was easily accessible to the participants and, second, to ensure that the sessions would not be interrupted because of noise.

The Research team consisted of the principal researcher (PR) and a bilingual (English/isiXhosa) RA, who acted as an observer and recorded the verbal and non-verbal responses of the participants. The focus group sessions were conducted primarily in English, with some questions being asked in isiXhosa by the bilingual $\mathrm{RA}$, when required.

At the start of each focus group session the PR, once again, explained the purpose of the focus group, confidentiality and the right to leave at any stage during the study. To ensure free and open discussion the PR also pointed out that there were no right or wrong answers. Thereafter, those who agreed to participate were requested to sign consent and group-binding confidentiality forms. The RA was also required to sign the group-binding confidentiality form at the start of each FGD session.

Four focus groups included ten (10) persons each, while the fifth group started out with eight (8) participants. However, $10 \mathrm{~min}$ into the discussion, one participant asked to be excused, leaving this fifth group with seven (7) persons. The PR developed a focus group guide to ensure consistency across all groups (Krueger, 2002). The questions included in the focus group guide are presented in Table 1.

Each session, which lasted between $45 \mathrm{~min}$ and $1 \mathrm{~h}$, was audiotaped. The FGDs continued until data saturation was reached, and this was judged to have been reached after five sessions that included a total of 47 participants. At completion of each FGD session the PR and RA met for debriefing to compare and collate notes taken by the RA, consequently developing additional field notes (Krueger, 2002). Each participant received an amount of R20.00 for transport as compensation.

Ethical approval for the Western Cape PURE and this study was obtained from the Research and Higher Degrees committee of the University of the Western Cape (project number 13/3/5). Informed, written consent was obtained from each participant. Confidentiality and anonymity was maintained

\section{Table 1 - Focus group discussion guide.}

Ice breaker

Tell us your name and which animal you think you are most like, and why

Introductory question

If a health programme, or club, is started in your area, would you be willing to join it, and why?

Key questions

Health messages are everywhere in magazines, posters, pamphlets and even on radio, what are the reasons for not following/implementing health messages?

Why do you not follow health advice/messages?

If you were to join a health group in your area, what would you want from the health group/programme? In other words, what would make you go to group meetings regularly?

What are the different ways through which you currently receive your health messages, and what are your feelings about the messages? What can be done to assist you to follow the health messages?

What health clubs/groups are available in your area?

Where would you want to receive your health messages?

Who do you want to receive your health messages from? 
by using participant numbers, instead of participant names on all study material.

\subsection{Trustworthiness}

After completion of each FDG, the summary of the discussions was read to the participants to ensure the researcher had an accurate account and understanding of their views. The transcripts were reviewed by two trained research assistants who compared the transcripts with the respective audiotaped recordings to ensure accuracy in the translations. The field notes also assisted in augmenting the accuracy of the transcripts. The PR and the study supervisor (SS) independently reviewed the transcripts, data analysis process and the emerging themes. This was done to reduce the possibility of bias and to obtain additional insights into themes and interpretations. Once the PR and SS reached an agreement on the final codes and themes, these were reviewed by the study's co-supervisor to ensure that there were no inconsistencies between the PR and SS.

\subsection{Data analysis}

The data were transcribed verbatim and translated into English, where required. The data were analysed using the summative content analysis approach. Atlas ti software [ATLAS. ti 7 for Windows, Berlin, Germany] was used to facilitate the coding and organisation of themes for analysis (Krueger \& Casey, 2000). The PR and SS independently read the transcripts and identified codes based on keywords and recurrent issues that emerged from the data. Then the PR and SS discussed any differences until consensus was reached on the codes. In total, 80 codes were identified. The codes were grouped into nine categories, and finally into four themes.

\section{Results}

The FGD participants ranged in age from 35 to 70 years, and were grouped according to their age and gender, to encourage free discussion. The groups predominantly comprised women. The four major themes identified were: practical aspects of implementation and adherence to intervention programmes; participants' expectations of intervention programmes; aspects influencing participants' acceptance of interventions; and participants' preferences for health message dissemination (Table 2).

\subsection{Practical aspects of implementation and adherence to intervention programmes}

\subsubsection{Challenges}

Healthy food was perceived to be expensive and since majority of the participants were unemployed, they lacked the financial means to purchase the recommended food and beverages:

Okay sisi... the problem is, it is because there is poverty in other houses, one cannot eat a special diet ... when there is a pot that is cooked, one cannot have another pot aside... as Black people we eat as a family.

We are poor...many people in the house...all must eat... [it is] not right [that] only some eat and others don't have to eat... healthy food is expensive.

Access to facilities where intervention programmes were being offered was limited, and personal safety was threatened:

Clinic is far and you have to walk over a field in the dark... [one can] get robbed and even raped ...here are more hospitals whereby [so] they can come closer; we talk about the distance...

Peer pressure and the lifestyle modifications were considered to be too difficult:

It is difficult to do those things... stop smoking, drinking...

You decide on your own if you want to stop smoking and drinking, you do not need a club for that...

If you don't drink or smoke with your friends, then they will not let you join them

A lack of education, food preferences and preferences by family members guided food intake:

You cannot read how are you going to see it?

We are not used to the taste of whole-wheat breads and cottage cheese

We like the junk foods... fatty food is mos [indeed] nice

I sometimes cook with oil and water but then my family [sic] don't eat

\subsubsection{Personal feelings}

Participants had a negative attitude towards making lifestyle changes, and questioned whether health messages were really beneficial to their health:

No, it's because we like to disagree to what the doctor says. (This remark was made when participants were asked for their reasons for not following health messages imparted by doctors).

I was saying, if a person cannot follow those pamphlets s/he wants to experience what is going to happen if $\mathrm{s} /$ he eats what $\mathrm{s} /$ he is advised not to eat, understand?

You get... you've got too much fruit and veggies at home... instead of eating that [those] fruit and veggies where does it [sic] go?... in the bin because you cannot see veggies and fruit as something that is nutritious (This remark was made when participants were asked why do not follow health messages specifically related to food intake). 
Table 2 - Identified themes, categories and subcategories (codes).

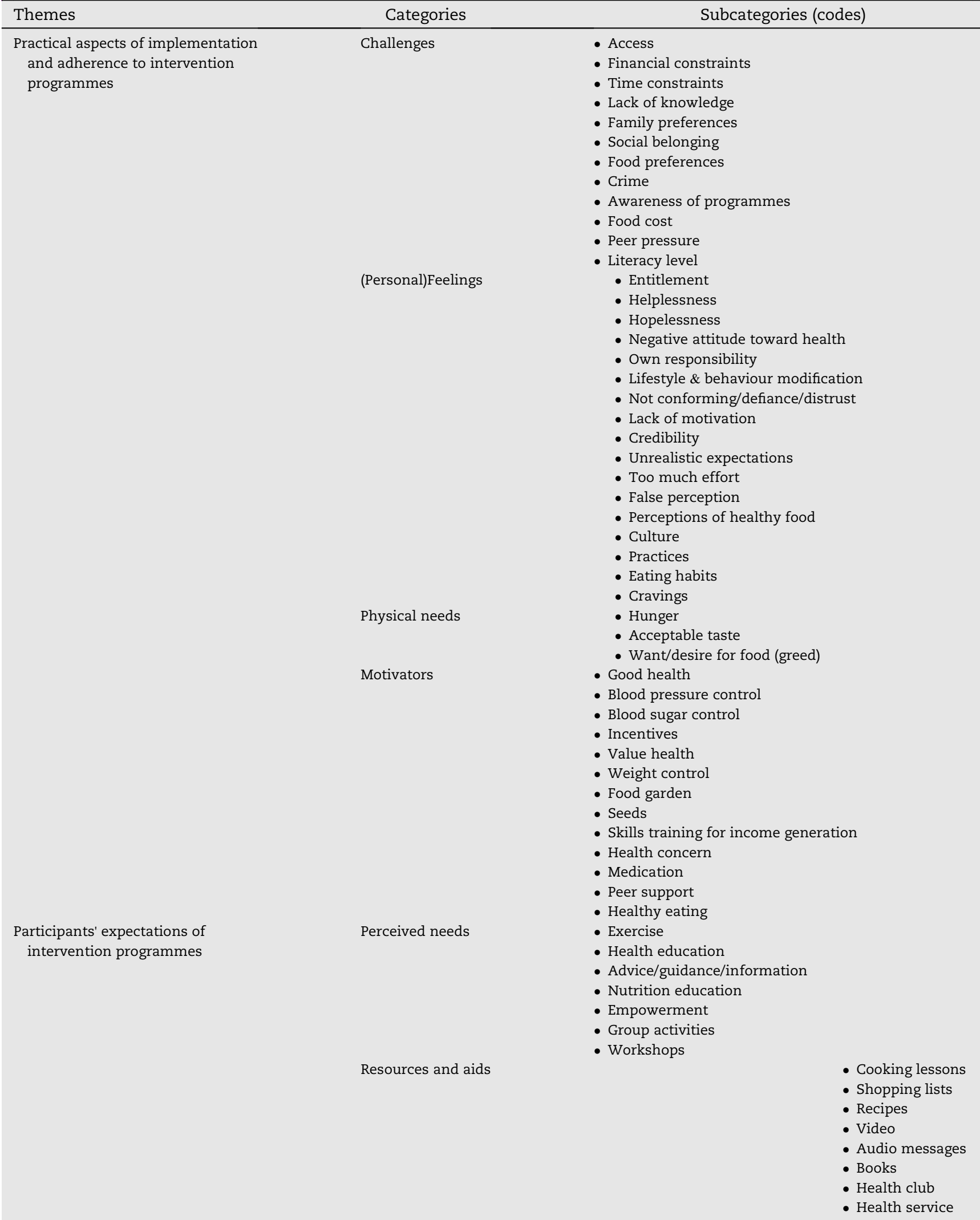


Table 2 - (continued)

\begin{tabular}{|c|c|c|}
\hline Themes & Categories & Subcategories (codes) \\
\hline $\begin{array}{l}\text { Aspects impacting participants' } \\
\text { acceptance of intervention } \\
\text { programmes }\end{array}$ & Acceptability & $\begin{array}{l}\text { - Health professional (doctor, nurse, dietitian) } \\
\text { - Home language } \\
\text { - Trained community member } \\
\text { - Pamphlets from credible source } \\
\text { - Spoken, face-to-face by a trained person } \\
\text { - Peer support } \\
\text { - Sharing of problems } \\
\text { - Resolution of problems }\end{array}$ \\
\hline \multirow[t]{2}{*}{$\begin{array}{l}\text { Participant preferences for } \\
\text { health message dissemination }\end{array}$} & $\begin{array}{l}\text { Mode of message } \\
\text { dissemination }\end{array}$ & $\begin{array}{l}\text { - Oral explanation of poster } \\
\text { - Community newspaper } \\
\text { - Magazine } \\
\text { - Television } \\
\text { - Radio } \\
\text { - Internet } \\
\text { - Cellphone applications }\end{array}$ \\
\hline & $\begin{array}{l}\text { Place of message } \\
\text { dissemination }\end{array}$ & $\begin{array}{l}\text { - Public places } \\
\text { - Public transport } \\
\text { - Supermarkets } \\
\text { - Schools } \\
\text { - Clinics } \\
\text { - Health facilities } \\
\text { - Health club }\end{array}$ \\
\hline
\end{tabular}

I grew up eating the meats, why must I stop now because they tell me to at the clinic? How can the doctor know me better than myself?

It is like vegetables are sometimes very cheap, but we don't want to eat vegetables...we are ignorant...just want to eat fries because that is nice...

Yes it is what the heart wants...greed, yes, it is greed

\subsubsection{Motivators}

A concern for their health was expressed by participants' receptiveness to having community-based CNCD health clubs:

It will help me with my weight... blood pressure

Actually, it's unwise not to go there, not to do that ... it's sort of guidance mos, [not so (?)] they are guiding you to do that for your health

Peer support was a great lure for attending a communitybased CNCD health clubs, however, some expressed the desire for incentives to ensure their attendance/ participation:

.... and as a matter of fact, when you are at a club...share information... each shares advice with the other... you not the only one with the problem.

Most of us come from disadvantaged backgrounds... good if they bring soup and it's for free... cannot see why I would stay at home and not come to health club;
They can give us stuff to make us come, like food or maybe money

We can start a food garden...as long as you provide the seeds."

\subsection{Participants' expectations of intervention programmes}

\subsubsection{Perceived needs}

A great need for information, resources and aids, and exercise classes was expressed:

Information which is going to help you and help others

Exercise and information how to be healthy.

We want recipes and lists of food and drinks to buy

Show us how to cook the healthy food.

\subsection{Aspects influencing participants' acceptance of interventions}

\subsubsection{Acceptability}

A preference was indicated for CNCD intervention health messages to be disseminated face-to-face by health professionals, preferably in their home language:

Cause why, its eh-h, you can't see something on TV and you believe that. You must go to someone like... like you ...

There are many fakes now, why must I believe? I must believe when I see like this face-to-face"

I need it to be explained to me that it goes like this and this... another person will speak in English, I do not understand 
English... how is it going to be clear when this person is speaking English?

\subsection{Participants' preferences for health message dissemination}

\subsubsection{Mode of message dissemination}

Even though some participants found all modes of health message dissemination in CNCD intervention acceptable, a preference for the oral/spoken format (one-on-one or group counselling, sessions and demonstrations) was expressed. The younger participants were keen to receive health messages via their cell phones:

No, if you think we are going to follow posters, to me it will be wrong you see, it will be wrong to me under [sic, for] the reasons I have already mentioned.

How will I believe that the person is a [for] real or s/he is a fake?

It will be better if someone show[s] us than a poster.

Posters are okay, but it is at the clinic and when you go home, you forget what it said" and "Pamphlets are better... take it home and read it again.

We can get videos of health on our phone

Someone should make APPS for phones; I would like to get health messages on my phone

\subsubsection{Place of message dissemination}

There was consensus that CNCD intervention health messages be disseminated ubiquitously:

Everywhere, bus, train, supermarket, schools... anywhere as long as you are going to get the message loud and clear.

Findings unique to this study were that some participants did not acknowledge health as their responsibility and expected incentives for attending health club meetings. A sense of entitlement and unrealistic expectations also featured strongly during the FGDs, with the participants expecting to be provided with food parcels, food and even money to encourage them to regularly participate in health club meetings. In addition, the participants' distrust of health messages disseminated via mass media (radio, television), questioning the source's credibility, because of a lack of proof of the health message disseminator's qualification, was also in stark contrast to other studies' findings.

\section{Discussion}

This study revealed that peer pressure, personal and family preferences and the perception that lifestyle changes are difficult resulted in participants being resistant to change their current diet and lifestyle habits. Similarly, previous research showed that the implementation of, and adherence to lifestyle changes are influenced by people's social environment and personal characteristics (Levesque, Li, \& Pahal, 2012; Mayega, Etajak, Rutebemberwa, Tomson, \& Kiguli, 2014; Muchiri, Gericke, \& Rheeder, 2012; Steyl \& Phillips, 2014).

Participants also questioned the benefits of health interventions probably because of clearly visible consequences of not conforming to recommended actions not being disseminated. Similar findings were reported in a recent study by Murray et al. (2013) where participants did not conform to health interventions because of their disbelief in health messages. Financial constraints, fear for personal safety, lack of transport and access to facilities where CNCD intervention programmes were offered also detracted from participants' ability to implement and adhere to CNCD intervention health messages.

Cultural and eating traditions were a challenge to participants because of the culturally-insensitive health messages which often recommend foods that they do not traditionally consume and also perceived as costly and not readily available in their community. These findings are in line with those reported in previous studies that healthy food is perceived to be costly and that readily available foods in an area influence eating behaviour (Farhamand, Tehrni, Amiri, \& Azizi, 2012; Mayega et al., 2014; Muzigaba \& Puoane, 2014; Verstraeten et al., 2014).

Besides information about CNCD, participants also expected resources (recipes), cooking lessons and exercise classes, to be part of a CNCD intervention programme. The participants were more likely to believe a health message, if this was delivered face-to-face by a health professional, or any other person they knew to be trained as a health professional. Their preferred health message disseminator was, in order of preference, a doctor, nurse, other health professional and trained community members (community health care workers). This may be as a result of the fact that these health professionals are regarded as having expertise in health matters confirming the findings of Parker, Steyn, Levitt, and Lombard (2012), Parajuli, Saleh, Thapa, and Ali (2014) and Levesque et al. (2012). These authors found that adherence to interventions worked better when the doctor is the source of the information as this allowed patients to build a relationship with the person disseminating the health messages and facilitated discussing their problems.

Although traditional modes of message dissemination (poster, pamphlets and billboards) were acceptable to most participants, they still expected a health professional to explain the content of these materials in their home language. This might be driven by the fact that many of the older participants, in particular, were illiterate and/or unable to communicate in or understand English. Previous studies reinforce this finding that language barriers impact on people's adherence to health interventions ( $\mathrm{Hu}$, Amirehsani, Wallace, \& Letvak, 2013; Mumu, Saleh, Ara, Afnan, \& Ali, 2014; Sentell \& Braun, 2012).

The dissemination of health messages via television, radio, magazines and community newspapers were acceptable to many of the participants because of a lack of proof of the health message disseminator's qualification. This strongly influenced their preference for receiving their health 
messages from a health professional (doctor, nurse) in their home language. Despite evidence in literature that mass media is regarded as an effective tool for health education, this mode for health message dissemination appears not to be effective in this particular study sample (Grilli, Ramsay, \& Minozzi, 2008; Martin, 2014).

Interestingly, only the younger participants viewed receiving health messages via a cell phone as acceptable. This finding concurs with the finding of a recent study in Canada but is in sharp contrast with those of a recent South African study where most participants regarded receiving health messages via cell phones (SMS-text messages) quite acceptable, with some even crediting these messages for their adherence (Afshar et al., 2012; Leon, Surender, Bobrow, Muller, \& Farmer, 2015).

\section{Limitations and recommendations}

Focus groups predominantly comprised females, which might have influenced the data collected. The researcher had difficulty recruiting men to participate in the focus group sessions, which might have been because they were at work when the FGDs were conducted. Meetings at night were not advised, because of the unsafe neighbourhood, and the men arriving home late from work. The study sample was isiXhosaspeaking participants, with many being unable to speak English. However, this issue was addressed by having a bilingual (English/isiXhosa) RA present.

Our study results cannot be generalised to other communities in the country since the research design possibly caused the study sample not be representative of the entire Langa community, and focussed only on one community. However, since each community is unique with its own contextual challenges, conducting similar studies in other communities could provide valuable information. These findings could inform interventions for CNCD.

Based on the findings of this study that resource-limited communities need education, access to culturally-sensitive recipes, shopping advice and instruction on healthy food preparation, future research could address the development of resources. Not only will this need be fulfilled, but its impact on implementation and adherence to CNCD intervention programme health messages will need to be evaluated.

\section{Conclusions}

This study revealed that although the participants found the methods and modes used to disseminate CNCD intervention programme health messages acceptable, they had difficulty with implementing and adhering to these messages for various reasons. New findings were that this study population had unrealistic expectations and showed distrust of health messages not disseminated face-to-face. Even though general guidelines are needed, community-based research should be done to design context-based intervention programmes with health messages tailored for the relevant population.

\section{R E F E R E N C E S}

Afshar, A. E., Weaver, R. G., Lin, M., Allan, M., Ronksley, P. E., Sanmartin, C., et al. (2012). Capacity and willingness of patients with chronic non-communicable diseases to use information technology to help manage their condition: A cross-sectional study. CMAJ Open. http://dx.doi.org/10.9778/ cmajo.20130070 (Accessed 15 October 2015).

Alwan, A., \& MacLean, D. R. (2009). A review of noncommunicable disease in low- and middle-income countries. Journal of International Health, 1, 3-9.

City of Cape Town. (2011). Census suburb Langa. https://www. captwon.gov.za/en/stats/2011censusSuburb/2011_Census_ CT_Suburb_Langa_Profile.pdf (Accessed 15 July).

Dalal, S., Beunza, J. J., Volmink, J., Adebamowo, C., Bajunirwe, F., Njelekela, M., et al. (2011). Non-communicable diseases in Sub-Saharan Africa: What we know now. International Journal of Epidemiology, 40, 885-901.

Department of Health. (2006). National guideline: Non-communicable diseases (NCDs): A strategic vision. Pretoria: Department of Health.

Drozek, D., Dieh, H., Nakazawa, M., Kostohryz, T., Morton, D., \& Shubrook, J. H. (2014). Short-term effectiveness of a lifestyle intervention program for reducing selected chronic disease risk factors in individuals living in rural Appalachia: A pilot cohort study. Advances in Preventive Medicine. http://dx.doi.org/ 10.1155/2014/798184/ (Accessed 11 August 2015).

Ebrahim, Z., de Villiers, A., \& Ahmed, T. (2014). Factors influencing adherence to dietary guidelines: A qualitative study on the experiences of patients with type 2 diabetes attending a clinic in Cape Town. JEMDSA, 19(2), 76-84.

Ezzati, M., \& Riboli, E. (2012). Can non-communicable diseases be prevented? Lessons from studies of populations and individuals. Science, 337, 1482-1487.

Farhamand, M., Tehrni, F. R., Amiri, P., \& Azizi, F. (2012). Barriers to healthy nutrition: Perceptions and experiences of Iranian women. BMC Public Health, 12, 1064. http://www. biomedcentral.com/147-2458/12/1064 (Accessed 15 October 2015).

Ganiyu, A. B., Mabuza, L. H., Malete, N. H., Govender, I., \& Ogunbanjo, G. A. (2013). Non-adherence to diet and exercise recommendations amongst patients with type 2 diabetes mellitus attending extension II clinic in Botswana. African Journal of Primary Health Care and Family Medicine, 5(1). http:// dx.doi.org/10.4102/phcfm.v5i1.457. Art No.:457 (Accessed on 16 August 2016).

Gortmaker, S. L., Swinburn, B. A., Levy, D., Carter, R., Mabry, P. L., Finegood, D. T., et al. (2011). Changing the future of obesity: Science, policy, and action. Lancet, 378, 838-837.

Grilli, R., Ramsay, C., \& Minozzi, S. (2008). Mass media interventions effects on health services utilisation (review). Cochrane Database of Systematic Reviews, 2002(1). http:// dx.doi.org/10.1002/14651858.CD000389. Art. No.: CD000389 (Accessed 15 October).

Herrera-Cuenca, M., Castro, J., Mangia, K., \& Correa, M. A. (2014). Are social inequalities the reason for the increase in chronic non communicable diseases? A systematic review. Journal of Diabetes, Metabolic Disorders \& Control, 1(3), 17-24.

Hu, J., Amirehsani, K., Wallace, D. C., \& Letvak, S. (2013). Perceptions of barriers in managing diabetes: Perspectives of Hispanic immigrant patients and family members. The Diabetes Educator, 39(4), 494-503. http://tde.sagepub.com/ content/39/4/494 (Accessed 5 October).

Hunter, D. J., \& Reddy, K. S. (2013). Non-communicable diseases. The New England Journal of Medicine, 369, 1336-1343. 
Isaacs, A. A., Manga, N., le Grange, C., Hellenberg, D. A., Titus, V., \& Sayed, R. (2014). A snapshot of noncommunicable disease profiles and their prescription costs at ten primary healthcare facilities in the western half of Cape Town Metropole. South African Family Practice, 56(1), 43-49.

Krueger, R. A. (2002). Designing and conducting focus group interviews. http://www.eiu.edu/ ihec/KruegerFocusGroupInterviews.pdf (Accessed 15 August 2005).

Krueger, R., \& Casey, M. (2000). Focus groups in social research (3rd ed.). Thousand Oaks, CA: SAGE.

Lategan, R., van den Berg, V. L., \& Walsh, C. M. (2014). Body adiposity indices are associated with hypertension in a black, urban Free State community. African Journal of Primary Health Care and Family Medicine, 6(1). http://dx.doi.org/10.4102/ phcfm.v6i1.581. Art no.:581 (Accessed 16 July).

Leon, N., Surender, R., Bobrow, K., Muller, J., \& Farmer, A. (2015). Improving treatment adherence for blood pressure lowering via mobile phone SMS-messages in South Africa: A qualitative evaluation of the SMS-text adherence SuppoRt (StAR) trial. BMC Family Practice. www.biomedcentral.com/1471-2296/16/80 (Accessed 15 October).

Levesque, A., Li, H. Z., \& Pahal, J. (2012). Factors related to patients' adherence to medication and lifestyle change

recommendations: Data from Canada. International Journal of Psychological Studies, 4(2), 42-55.

Levitt, N. S., Steyn, K., Dave, J., \& Bradshaw, D. (2011). Chronic noncommunicable diseases and HIV-AIDS on a collision course: Relevance or health care delivery, particularly in lowresource settings - insights from South Africa. The American Journal of Clinical Nutrition, 94(Suppl), 1690S-1696S.

Li, D. (2013). Effect of the vegetarian diet on non-communicable diseases. Journal of the Science of Food and Agriculture, 94, 169-173.

Martin, J. D. (2014). Interventions that promote stroke awareness: A literature review. Journal of Community Health Nursing, 31, 20-33.

Masadeh, M. (2012). Focus group: Reviews and practices. The Journal of Applied Science and Technology, 2(10), 63-68.

Mayega, R. W., Etajak, S., Rutebemberwa, E., Tomson, G., \& Kiguli, J. (2014). "Change means sacrificing a good life": Perceptions about severity of type 2 diabetes and preventive lifestyles among people afflicted or at high risk of type 2 diabetes in Iganga Uganda. BMC Public Health, 14, 864. http:// www.biomedcentral.com/1471-2458/14/864 (Accessed 15 August 2011).

Mayosi, B. M., Flisher, A. J., Lalloo, U. G., Sitas, F., Tollman, S. M., \& Bradshaw, D. (2009). The burden of non-communicable diseases in South Africa. Health in South Africa, Series 4. Lancet, 374, 934-947.

Mayosi, B. M., Lawn, J. E., van Niekerk, A., Bradshaw, D., Karim, S. S. A., \& Coovadia, H. M. (2012). Health in South Africa: Changes and challenges since 2009. Lancet, 380, 2029-2043.

Merrill, R. M., Aldana, S. G., Greenlaw, R. L., Salberg, A., \& Englert, H. (2008). Chronic disease risk reduction with a community-based lifestyle change programme. Health Education Journal, 67(3), 219-230.

Muchiri, J. W., Gericke, G. J., \& Rheeder, P. (2012). Needs and preferences for nutrition education of type 2 diabetic adults in a resource-limited setting in South Africa. Health SA Gesondheid, 17(1). http://dx.doi.org/10.4102/hsag.v17i1.614 (Accessed 15 October 2009).

Muka, T., Imo, X., Jaspers, L., Colpani, V., Chaker, L., van der Lee, S. J., et al. (2015). The global impact of non-communicable diseases on healthcare spending and national income: A systematic review. European Journal of Epidemiology, 30, 251-277.

Mumu, S. J., Saleh, F., Ara, F., Afnan, F., \& Ali, L. (2014). Nonadherence to life-style modification and its factors among type 2 diabetic patients. Indian Journal of Public Health, 58(1), $40-44$.

Murray, J., Fenton, G., Homey, S., Bara, A. C., Hill, K. M., \& House, A. (2013). A qualitative synthesis of factors influencing maintenance of lifestyle behaviour change in individuals with high cardiovascular risk. BMC Cardiovascular Disorders, 13, 348. http://www.biomedicalcentral.com/1471-2261/13/48 (Accessed 15 October 2009).

Muzigaba, M., \& Puoane, T. (2014). Perceived and actual cost of healthier foods versus their less healthy alternatives. A case study in a predominantly black urban township in South Africa. East African Journal of Public Health, 8(4), 283-290.

Oli, N., Vaidya, A., \& Thapa, G. (2013). Behavioural risk factors of non-communicable diseases among Nepalese urban poor: A descriptive study from a slum area of Kathmandu. Epidemiology Research International. http://www.hindawi.com/ journals/eri/2013/329156 (Accessed 15 August 2011).

Parajuli, J., Saleh, F., Thapa, N., \& Ali, L. (2014). Factors associated with non-adherence to diet and physical activity among Nepalese type 2 diabetes patients; a cross sectional study. BMC Research Notes, 7, 758. http://www.biomedcentral.com/17560500/7/758 (Accessed 15 October 2001).

Parker, W., Steyn, N. P., Levitt, N. S., \& Lombard, C. J. (2012). Health promotion services for patients having noncommunicable diseases: Feedback from patients and health care providers in Cape Town, South Africa. BMC Public Health, 12, 503. http://www.biomedcentral.com/1471-2458/12/503 (Accessed 15 October 2001).

Puoane, T., Tsolekile, L., Sanders, D., \& Parker, W. (2008). Noncommunicable diseases. In P. Barron, \& J. Roma-Reardon (Eds.), South African health review 2008 (pp. 73-87). Durban: Health Systems Trust.

Rossier, C., Souri, A. B., Duthe, G., \& Findley, S. (2014). Noncommunicable disease mortality and risk factors in formal and informal neighborhoods, Ouagadougou, Burkina Faso: Evidence from a health and demographic surveillance system. PLoS One, 9(12), e113780. http://dx.doi.org/10.1371/ journal.pone/0113780 (Accessed 15 August 2012).

Sentell, T., \& Braun, K. (2012). Low health literacy, limited English proficiency, and health status in Asians, Latinos, and other racial/ethnic groups in California. Journal of Health Communication, 17(Suppl 3), 82-99.

Shisana, O., Labadarios, D., Rehle, T., Simbayi, I., Zuma, K., Dhansay, A., et al. (2013). South African national health and nutrition survey (SANHANES-1). Cape Town: HSRC Press.

Statistics South Africa. (2014). Mortality and causes of death in South Africa, 2013: Findings from death notification. http://www.stassa. gov.za (Accessed 15 October 2010).

Steyl, T., \& Phillips, J. (2014). Management of type 2 diabetes mellitus: Adherence challenges in environments of low socioeconomic status. African Journal of Primary Health Care, 6(1). http://dx.doi.org/10.4102/phcfm.v6i1.713 (Accessed 15 October 2010).

Teo, K., Chow, C. K., Vaz, M., Rangarajan, S., \& Yusuf, S. (2009). The Prospective Urban Rural Epidemiology (PURE) study: Examining the impact of societal influences on chronic noncommunicable diseases in low-, middle- and high-income countries. American Heart Journal, 158(1), 1e1-7e1.

Verstraeten, R., van Royen, K., Ochoa-Avilés, A., Penafiel, D., Holdsworth, M., Donoso, S., et al. (2014). A conceptual framework for healthy behavior in Ecuadorian adolescents: A qualitative study. PLoS One, 9(1), e87183. http://dx.doi.org/ 10.1371/journal.pone/0087183 (Accessed 15 August 2011).

Whiteside, A. (2014). South Africa's key health challenges. The Annals of the American Academy, 652, 166-185.

World Bank. (2015). Classification of economies by income and region. http://www.worldbank.org/depweb/beyond/beyondco/beg_ce. pdf (Accessed 15 October 2010). 